\title{
Aquecimento Global
}

\section{ConferÊnCIA do CLIMA De Copenhaga}

Apesar do enorme mediatismo, a Conferência do Clima das Nações Unidas realizada em Copenhaga (de 7 a 18 de Dezembro passado) parece ter ficado aquém das expectativas. Esperava-se um compromisso global mas ficaram apenas recomendações. Uma posição mais fraca do que a conseguida em Quioto, embora nessa altura os EUA tenham sido os grandes ausentes.

Neste encontro, do ponto de vista político, a Europa e o denominado grupo G8 (EUA, Japão, Reino Unido, Itália, Alemanha, França, Canadá e Rússia) parecem ter perdido o protagonismo que vinham evidenciando. Apesar do resultado conseguido, esta conferência trouxe para a arena os EUA e a China, emergindo também o Brasil e a Índia como intervenientes relevantes para qualquer acordo global. Aliás a própria ONU parece ter perdido protagonismo para os EUA. A "organização do mundo" em blocos de países consoante o seu grau de desenvolvimento (desenvolvidos e em vias de desenvolvimento) foi alterada nesta conferência.

O G8 tinha anunciado, antes da Conferência de Copenhaga, numa reunião realizada em L'Aquila, a intenção de manter o objectivo de limitar o aquecimento a não mais de $2^{\circ} \mathrm{C}$ em relação às temperaturas pré-industriais. Acordaram também que os países industrializados poderiam reduzir as emissões conjuntas dos gases com efeito de estufa em $80 \%$ até 2050 e, em conjunto com outros países, reduzir as emissões globais em $50 \%$ no mesmo período. Contudo, esta decisão foi adiada para as negociações de Copenhaga e nesta não foi possível conseguir um compromisso desse tipo.

Entretanto, segundo um estudo recente (O'Neill et al, Proc. Natl. Acad. Sci. USA, doi:10.1073/0903797109 (2010)), apenas uma mobilização em massa poderá, eventualmente, reduzir em $50 \%$ as emissões dos gases causadores do efeito de estufa até 2050, a menos que ocorra uma alteração radical dos padrões de desenvolvimento globais. Os esforços a desenvolver na segunda metade do século teriam, ainda assim, que ser enormes para conseguir limitar o aumento de temperatura a $2^{\circ} \mathrm{C}$ em 2100 . O estudo sublinha as dúvidas existentes sobre o objectivo de $2^{\circ} \mathrm{C}$, usado por muitos políticos como instrumento para adiarem compromissos de curto prazo mais credíveis. $O$ estudo fornece, contudo, novos argumentos para as discussões sobre quando tem que ocorrer uma redução maciça das emissões e quanto podem custar. Se o objectivo for limitar o aquecimento do mundo em rápido desenvolvimento e sem limitações de carbono, como é actualmente o caso, a $2^{\circ} \mathrm{C}$, o investimento cumulativo em energia terá que aumentar significativamente. (adaptado de Nature News de 11 de Janeiro).

\section{Aquecimento global e altera- ÇÕES CLIMÁTICAS}

O efeito de estufa, consistindo na retenção pelos gases da atmosfera (como dióxido de carbono e metano, principalmente) do calor (radiação infravermelha) que se gera na superfície da Terra a partir da radiação recebida do Sol, está na origem da relativamente pequena amplitude térmica diária à superfície da Terra, tornando possível o desenvolvimento da vida, como a conhecemos. O que actualmente se discute é o efeito da acumulação de gases absorvedores de radiação infravermelha na atmosfera (o que exclui os seus maiores constituintes, azoto e oxigénio), que podem estar a conduzir a um aumento da temperatura média e, consequentemente, a uma alteração dos equilíbrios atmosféricos existentes há milhares de anos atrás, em particular, até ao início da revolução industrial (séc. XVIII).

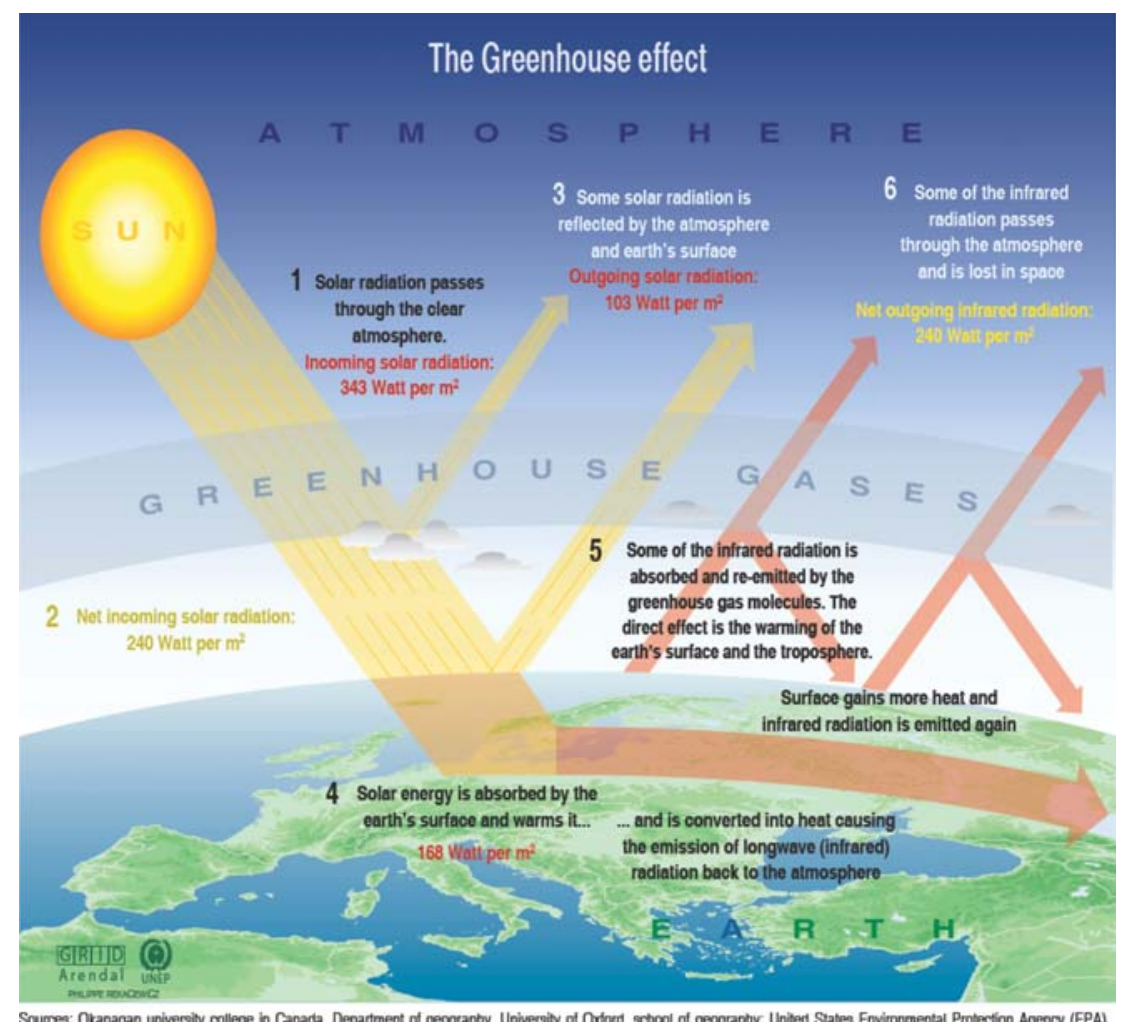

Sources: Otanagan universily college in Canada, Department of geography, University of Oxtord, scticol of geography, United States Environmental Protection Agency (EPA), Wastington; Cimate change 1995, The science of cimate change, contitibution of worting group 1 to the second assessment report of the intergovernmental panel on dimate change, UNEP and WMO, Canorioge university press, 1996.

Figura 10 efeito de estufa (fonte: http://maps.grida.no/go/graphic/greenhouse-effect) 
Em 1895, o cientista sueco Arrhenius, recorrendo a conceitos físicos básicos conseguiu perceber de que forma variações da concentração de gases na atmosfera, em particular do dióxido de carbono, afectavam o balanço de calor na Terra. Estabelecendo uma correlação entre elevadas concentrações de dióxido de carbono na atmosfera e temperaturas atmosféricas mais elevadas, Arrhenius estabeleceu os fundamentos da investigação actual em alterações climáticas, a qual é dominada pela compreensão de que/ se um aumento contínuo da concentração de $\mathrm{CO}_{2}$ atmosférico, provocado essencialmente pela queima de com- bustíveis fósseis, é a razão principal pela qual o clima mundial está a aquecer tanto e tão rapidamente.

Apesar de a maioria dos cientistas que estudam o clima considerarem que o aquecimento global é de origem antropogénica, há no entanto outros que argumentam que não existe uma base científica suficiente que suporte essa conclusão.

Os factos indesmentíveis são que a concentração de dióxido de carbono atmosférico tem aumentado desde que a Revolução Industrial começou em 1700s, com o aumento mais signi- ficativo desde 1950; que este aumento é essencialmente devido à queima de combustíveis fósseis; que a temperatura global média tem aumentado desde 1850, com o aumento mais significativo desde 1970.

Há também dados que mostram uma correlação entre a concentração de $\mathrm{CO}_{2}$ atmosférico e a temperatura média global. Contudo, a unanimidade termina aqui. A questão central do debate reside na causa do aquecimento: se este resulta do aumento do nível de $\mathrm{CO}_{2}$ antropogénico ou se é apenas o resultado da variabilidade do clima natural da Terra.

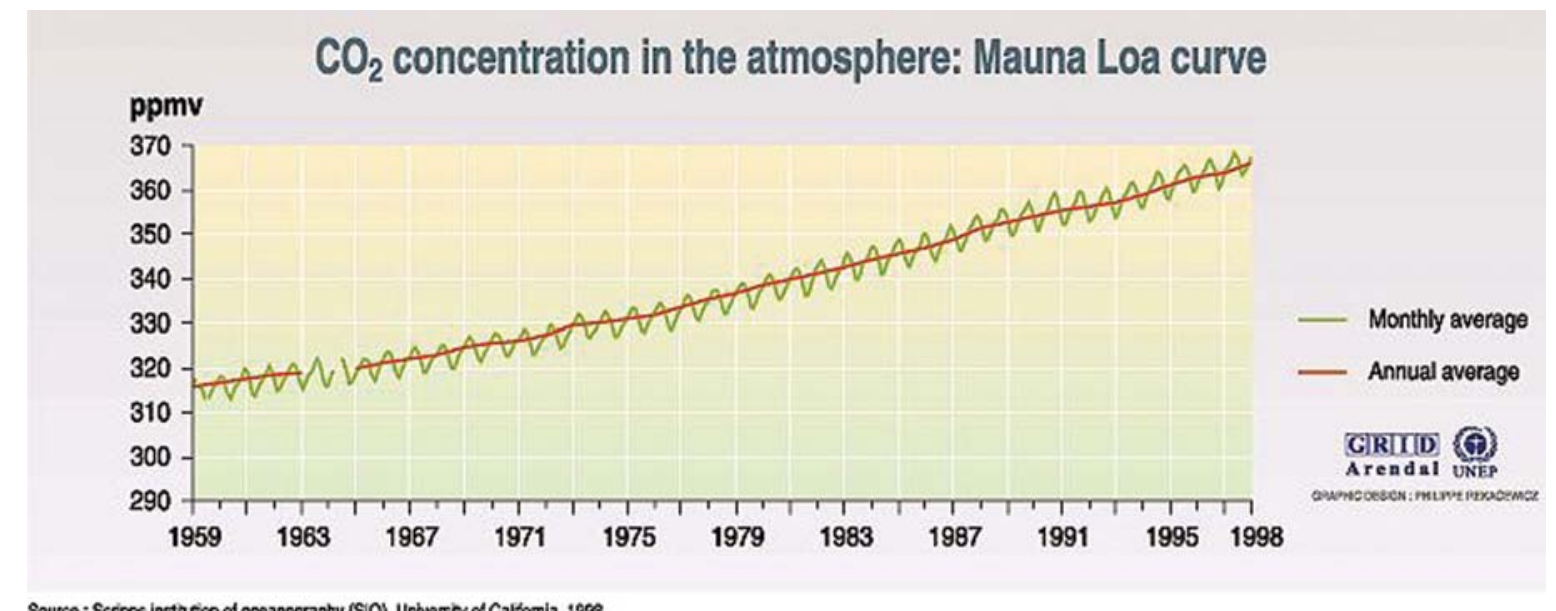

Figura 2 Evolução da concentração de $\mathrm{CO}_{2}$ na atmosfera (fonte: http://maps.grida.no/go/graphic/co2-concentration-in-the-atmosphere-1959-1998)

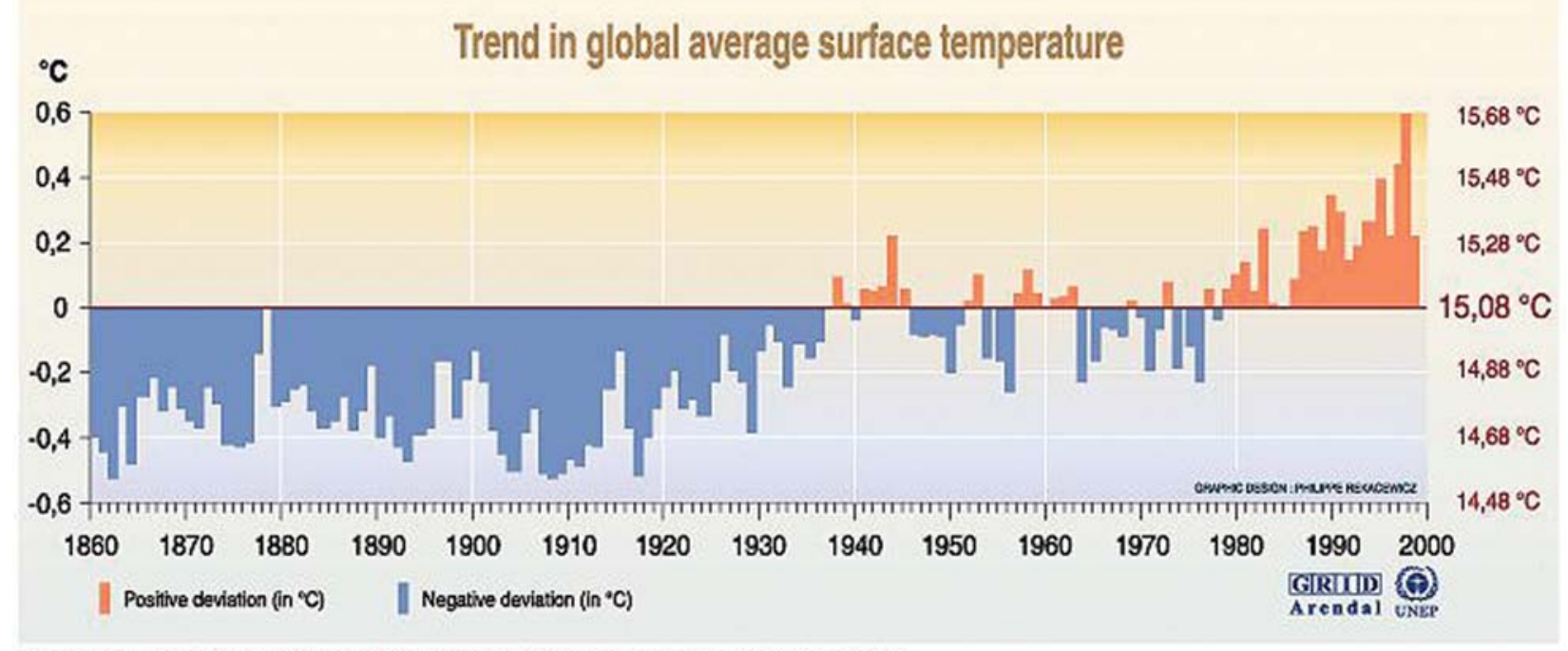

Souroe: School of emiromantal sclanoes, cimarc nesearch unit, univershy of East Angle, Nonwich, United Kngdom, 1989.

Figura 3 Evolução da temperatura global média (fonte: http://maps.grida.no/go/graphic/trends-in-global-temperatures) 


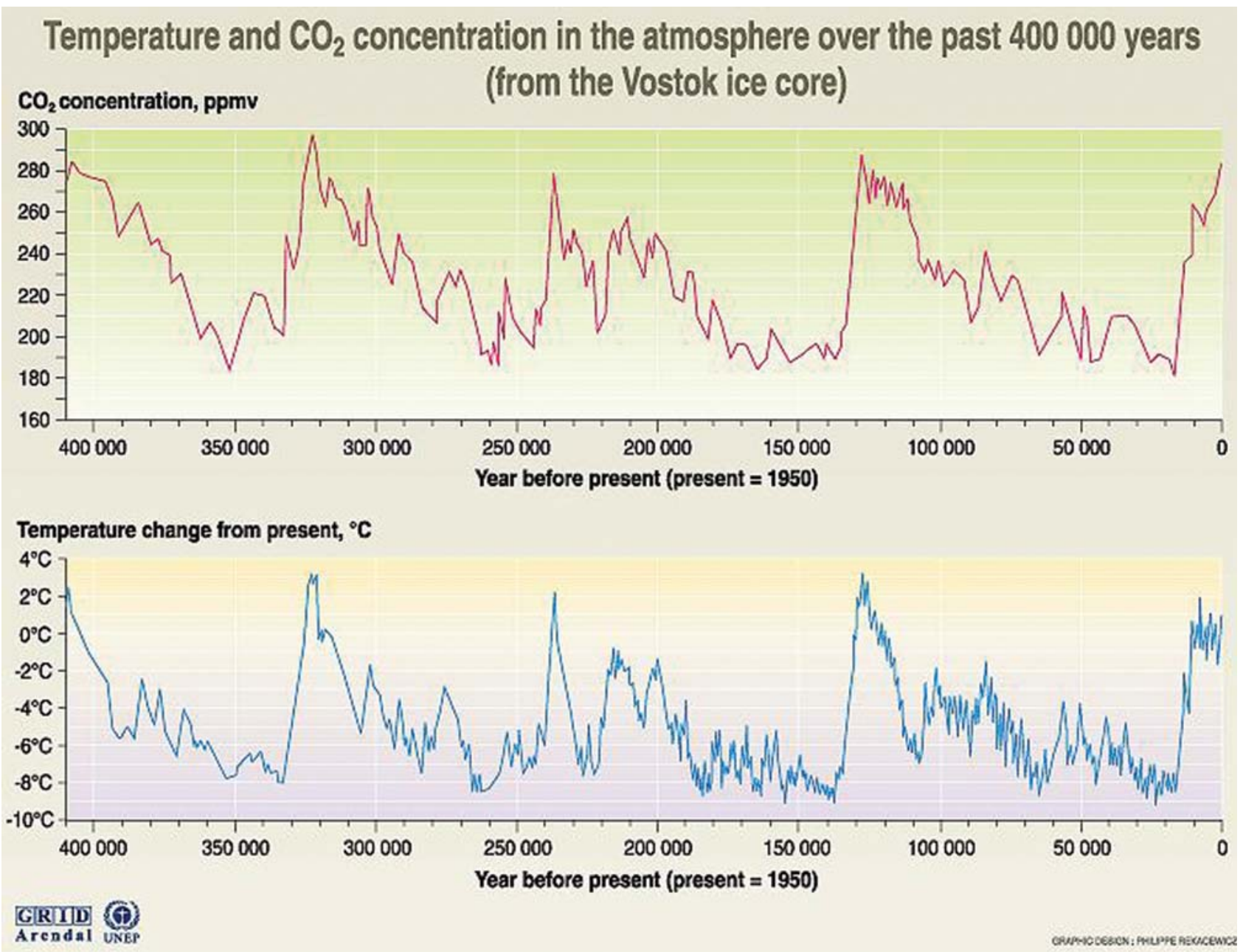

Source: J.R. Pelit, J. Jouzel, et al. Climate and atmospheric history of the pest 420000 ycars from the Vostok ibe core in Antarcica, Nature 399 (3UUne), DD 429-436, 1999.

Figura 4 Correlação entre a variação da temperatura e a variação da concentração de $\mathrm{CO}_{2}$ nos últimos 400000 anos (fonte: http://maps.grida.no/go/graphic/temperature-and-co2-concentration-in-the-atmosphere-over-the-past-400-000-years)

A opinião maioritária é a veiculada por relatórios divulgados nos últimos 20 anos pelo IPCC (Intergovernamental Panel on Climate Change), uma entidade criada pelas Nações Unidas, segundo a qual "o aquecimento do sistema climático é inequívoco, dado que há evidências para um aumento da temperatura global média do ar e dos oceanos, vasto degelo de neve e gelo, e um aumento global médio do nível do mar". Além disso, atribui a maior contribuição para o aquecimento verificado desde meados do século $\mathrm{XX}$, com probabilidade de $90 \%$, à actividade antropogénica. Os cépticos consideram que os $10 \%$ de probabilidade restante não é desprezável, apontando, pelo contrário, para que tais alterações de temperatura resultem de variabilidade climática natural. Estes agrupam-se em "negadores das alterações climáticas”, que acreditam que o período de aquecimento actual é apenas uma fase das variações de temperatura média da Terra e que o sistema climático é insensível às emissões de gases de efeito de estufa resultantes da actividade humana, e um segundo grupo que não concorda com a totalidade das conclusões do IPCC, duvidando que as alterações possam ser integralmente atribuídas a efeitos antropogénicos.

A teoria do clima baseia-se no pressuposto de que a Terra mantém um equilíbrio entre a energia solar que recebe sob a forma de radiação ultravioleta e luz visível que absorve e a quantidade de calor, sob a forma de radiação infravermelha, que reenvia para o espaço. De entre os factores que podem alterar este balanço, o dióxido de carbono é o único que está a variar significativamente. $\mathrm{O} \mathrm{CO}_{2}$ atmosférico aumento de cerca de 280 ppmv em 1750 para cerca de 380 ppmv hoje e o IPCC afirma que este aumento excede o intervalo natural de 180-300 ppmv, obtido por medidas em bolhas de ar retidas em gelo que datam de até há 800000 anos atrás. Além disso, a taxa de crescimento do $\mathrm{CO}_{2}$ reflecte apenas $55 \%$ das emissões estimadas como resultado da actividade humana, o que significa que a natureza sequestra actualmente cerca de metade do $\mathrm{CO}_{2}$ gerado pelos humanos. Contudo, de acordo com um estudo recente, a capacidade natural da Terra para sequestrar o $\mathrm{CO}_{2}$ parece estar a diminuir.

É de referir no entanto que todas moléculas presentes na atmosfera que absorvem radiação infravermelha contribuem para o efeito de estufa. A cada molécula é atribuído um potencial de aquecimento global. Assim, para o $\mathrm{CO}_{2}$, que serve de padrão, o potencial é de uma molécula ao longo de 100 anos. Para o metano o potencial de aquecimento é de 21, sendo 310 para $\mathrm{N}_{2} \mathrm{O}$ e 23900 para $\mathrm{SF}_{6}$. 


\section{The main greenhouse gases}

\begin{tabular}{|c|c|c|c|c|c|c|}
\hline Greenhouse gases & $\begin{array}{l}\text { Chemical } \\
\text { formula }\end{array}$ & $\begin{array}{l}\text { Pre-industrial } \\
\text { concentration }\end{array}$ & $\begin{array}{l}\text { Concentration } \\
\text { in } 1994\end{array}$ & $\begin{array}{c}\text { Atmospheric } \\
\text { lifetime (years) }\end{array}$ & $\begin{array}{l}\text { Anthropogenic } \\
\text { sources }\end{array}$ & $\begin{array}{l}\text { Global warming } \\
\text { potential (GWP)* }\end{array}$ \\
\hline Carbon-dioxide & $\mathrm{CO}^{2}$ & $280 \mathrm{ppmv}$ & $358 \mathrm{ppmv}$ & $50-200$ & $\begin{array}{l}\text { Fossil fuel combustion } \\
\text { Land use conversion } \\
\text { Cement production }\end{array}$ & 1 \\
\hline Methane & $\mathrm{CH}_{4}$ & 700 ppbv & $1720 \mathrm{ppmv}$ & $12-17$ & $\begin{array}{l}\text { Fossil fuels } \\
\text { Rice paddies } \\
\text { Waste dumps } \\
\text { Livestock }\end{array}$ & $21^{* *}$ \\
\hline Nitrous oxide & $\mathrm{N}_{2} \mathrm{O}$ & 275 ppbv & $312 \mathrm{ppmv}$ & $120-150$ & $\begin{array}{c}\text { Fertilizer } \\
\text { industrial processes } \\
\text { combustion }\end{array}$ & 310 \\
\hline CFCs & CFC12 & 0 & $503 \mathrm{pptv}$ & 102 & $\begin{array}{l}\text { Liquid coolants. } \\
\text { Foams }\end{array}$ & $125-152$ \\
\hline HCFCs & HCFC-22 & 0 & $105 \mathrm{pptv}$ & 13 & Liquid coolants & 125 \\
\hline Perfluorocarbon & $\mathrm{CF}_{4}$ & 0 & $110 \mathrm{pptv}$ & 50000 & $\begin{array}{l}\text { Production } \\
\text { of aluminium }\end{array}$ & 6500 \\
\hline Sulphur hexa-fluoride & $\mathrm{SF}_{6}$ & 0 & $72 \mathrm{pptv}$ & 1000 & $\begin{array}{l}\text { Production } \\
\text { of magnesium }\end{array}$ & 23900 \\
\hline
\end{tabular}

Note : pptv= 1 part per trillion by volume; ppbv= 1 part per billion by volume, ppmv= 1 part per million by volume - GWP for 100 year time horizon. " Includes indirect effects of tropospheric ozone production and stratospheric water vapour production. $\cdots$ On page 15 of the IPCC SAR. No
single lifetime for $\mathrm{CO}_{2}$ can be defined because of the different rates of uptake by different sink processes.

Source: IPCC radiative forcing report ; Climate change 1995, The science of climate change, contribution of working groupe 1 to the second assessment report of the intergovernmental panel on climate change, UNEP and WMO, Cambridge press university, 1996

Figura 5 Principais gases de efeito de estufa (fonte: http://maps.grida.no/go/graphic/main-greenhouse-gases)

O vapor de água é o gás de efeito de estufa mais abundante e influente. Contudo este não é considerado como um factor contribuindo directamente para o aquecimento global, sendo o seu efeito considerado como "feedback" nos modelos climáticos. Na globalidade, o vapor de água e as nuvens são responsáveis por $60 \%$ do efeito de estufa, seguindo-se $\mathrm{O}^{\mathrm{CO}_{2}}$ com cerca de $26 \%$ e depois, com pequenas contribuições, metano, ozono e outros gases. Na ausência de aquecimento por efeito de estufa natural a temperatura média da Terra seria de $-18{ }^{\circ} \mathrm{C}$. Este efeito de estufa natural aumenta a temperatura para cerca de $33^{\circ} \mathrm{C}$.

Os cientistas que investigam o clima dependem de medidas de temperatura, à superfície ou medidas com satélites, para as suas previsões. Contudo, as condições em que estas medidas são efectuadas têm sido alvo de controvérsia.

Refira-se no entanto que, mais do que as medidas absolutas, o que mais interessa os cientistas são as variações. Para estudar períodos de tempo longos, os cientistas recorrem a registos históricos e dados recolhidos de gelo, anéis das árvores e sedimentos marítimos, o que lhes permite recuar no tempo. Mas também estes estudos são pontos quentes de debate sobre as alterações climáticas.

O facto de quer a temperatura quer a concentração de $\mathrm{CO}_{2}$ terem valores mais altos e mais baixos (ver Fig. 4) do que hoje é usado para fundamentar que a variabilidade natural do clima é a norma e que o impacto da actividade humana não é identificável, ou seja, que há um aquecimento pequeno ou mesmo nulo resultante da actividade antropogénica.

A disputa permanece activa. Havendo uma só Terra para estudar, o IPCC usou 18 modelos diferentes para estabelecer as suas conclusões, o que levou a vários resultados. Verificaram que se os efeitos da actividade antropogénica não fossem incluídos nesses modelos não se conseguia obter a tendência de variação da temperatura observada. Contudo, os cépticos argumentam que se trata afinal da escolha de parâmetros que se ajustam às variações observadas!

A figura 4 mostra que, nos últimos 400000 anos, as alterações de temperatura anteciparam as alterações da concentração de $\mathrm{CO}_{2}$. Contudo, nos últimos 100 anos esta relação foi alterada, dado que as alterações da concentração de $\mathrm{CO}_{2}$ precederam as alterações de temperatura. Enquanto prova do efeito da actividade antropogénica, este argumento não é contudo consensual.

Em conclusão, apesar da controvérsia, a posição maioritária parece ser, no entanto, a de que o conjunto dos dados recolhidos constitui uma prova avassaladora da influência da actividade humana nas alterações climáticas, embora existam ainda incertezas em relação às previsões das consequências futuras. 


\section{Sea level rise due to global warming}

\section{Sea level rise over the last century}

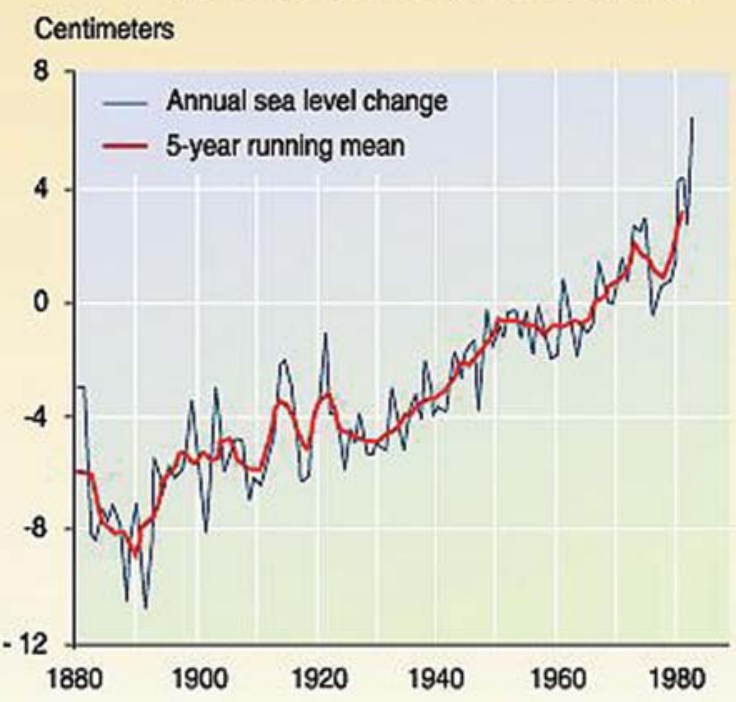

Sea level rise scenarios for 2100

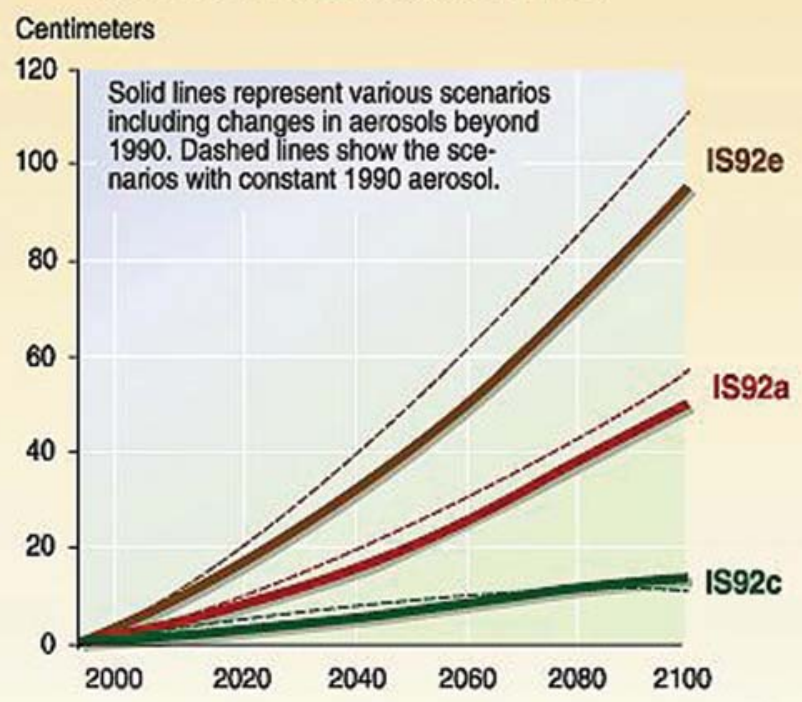

GIRIID (O)

A rendal UNEP

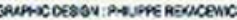

Souree: Cimato change 1595, The soimeo of dimale change, contibulion ol working group 1 to tha socend asseesment repont of the intergevernmental panel on efimase change, UNEP and VaNO, Cambridge unhersty press, 1995; Sea level rise over the last contury, adapted from Comitz and Lebedeff, 1987.

Figura 6 Previsões de evolução do nível do mar (fonte: http://maps.grida.no/go/graphic/sea-level-rise-due-past-and-scenarios-due-to-global-warming)

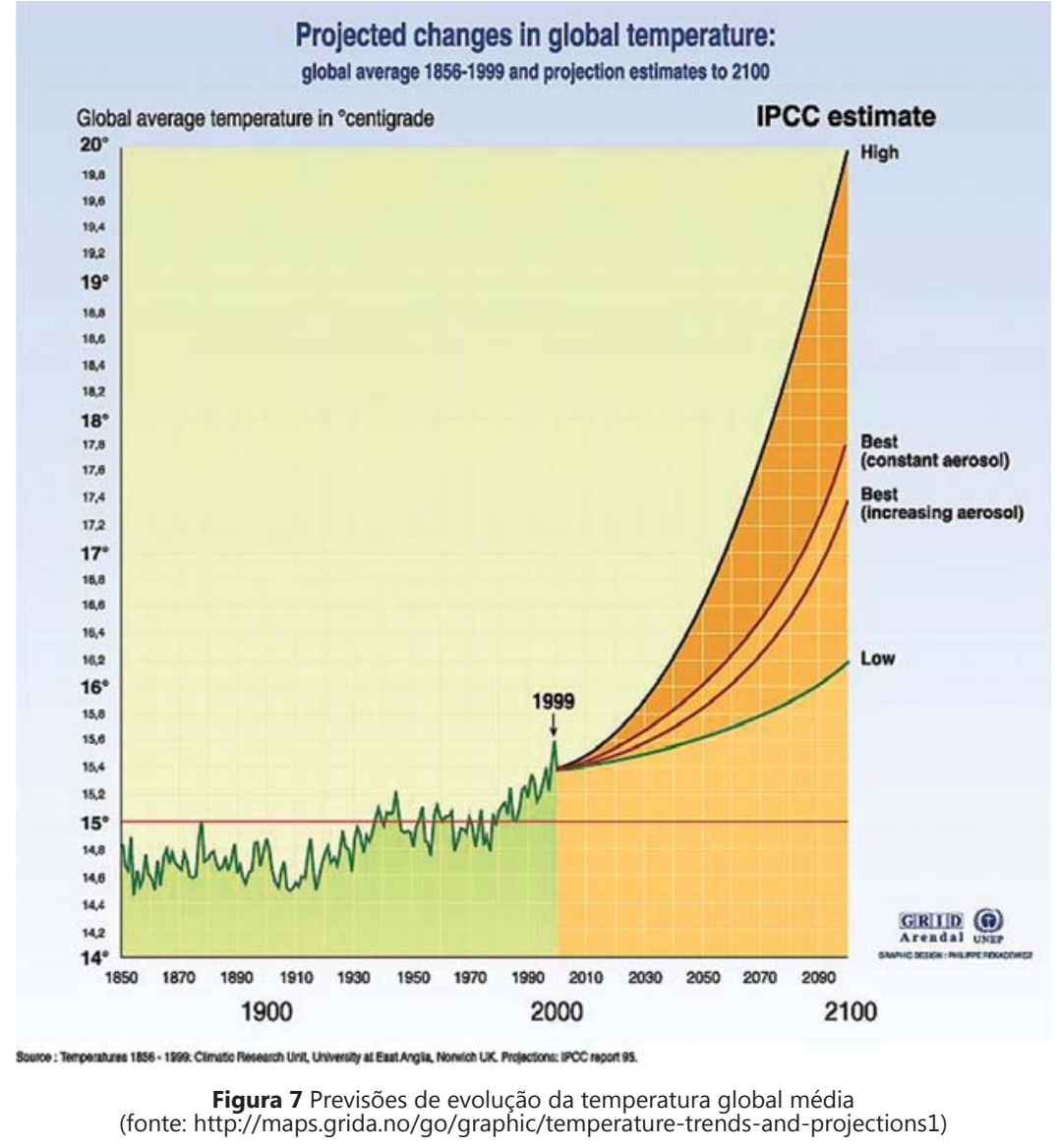

3. Captura e retenção de carbono

Sendo o dióxido de carbono apontado como o principal causador do aqueci- to e do desenvolvimento de processos em que a sua produção seja minimizada. No número de 25 de Setembro a revista Science fez um apanhado das ideias e esforços em desenvolvimento para capturar e armazenar o dióxido de carbono.

Claro que, se for química e tecnologicamente viável a utilização de dióxido de carbono como matéria-prima, poderemos encontrar uma solução útil para o excesso de dióxido de carbono. Apesar de haver estudos em curso, em particular sobre catalisadores que possam promover essa transformação, a tarefa não se apresenta fácil (mesmo do ponto de vista termodinâmico). É apresentado um limite de aumento de temperatura de $2^{\circ} \mathrm{C}$ em relação à época que precedeu a Revolução Industrial. As previsões das alterações climáticas indicam que é necessário atingir uma redução do $\mathrm{CO}_{2}$ antes de 2020 .

De facto, na Conferência do Clima das Nações Unidas de 2007 em Bali houve vários apelos para que se reduzam em $50 \%$ as emissões globais de gases de efeito de estufa até 2050 , para que se evite um aumento que ultrapasse o limite de $2^{\circ} \mathrm{C}$. 
A decisão de limitar o aumento de temperatura a $2^{\circ} \mathrm{C}$ é essencialmente de natureza política. Segundo alguns modelos, uma concentração de dióxido de carbono equivalente, $\mathrm{CO}_{2} \mathrm{e}$ (que reflecte o efeito dos vários gases de efeito de estufa, para além do $\mathrm{CO}_{2}$ ) de 550 ppmv (partes por milhão em volume) sugere $82 \%$ de probabilidade de ultrapassar o limite de $2^{\circ} \mathrm{C}$, enquanto que para se conseguir $93 \%$ de probabilidades de não se ultrapassar esse limite, é necessário limitar a concentração de $\mathrm{CO}_{2}$ e a 350 ppmv, ou seja, abaixo dos níveis actuais. Assim, há quem sugira um limite mais realista de aumento de $4^{\circ} \mathrm{C}$, o qual, mesmo assim, só será conseguido com uma rápida acção.

A concentração actual de $\mathrm{CO}_{2}$ é de cerca 380 ppmv, e a concentração de
$\mathrm{CO}_{2}$ e é de cerca de 455 ppmv. Muitos cientistas acreditam que 450 ppmv é a concentração máxima que podemos permitir se queremos evitar uma perturbação do clima.

\section{SOBRE O CIClO DO CARBONO}

O carbono circula através das criaturas vivas, da atmosfera, oceanos e a própria Terra, num balanço impressionante. A fixação do carbono pelos organismos terrestres e marítimos ocorre através da fotossíntese. Os animais consomem outros organismos e queimam carbo-hidratos para obterem energia, libertando $\mathrm{CO}_{2}$ através da respiração e por decomposição após a sua morte. Ao longo de períodos de tempo mais longos do que a presença dos humanos, a formação de carbono igualou sensivelmente o seu consu- mo. A adição de $\mathrm{CO}_{2}$ pelos humanos através da queima de combustíveis fósseis veio alterar este equilíbrio. $\mathrm{CO}_{2}$ é absorvido pelas águas frias dos oceanos e as correntes frias a latitudes elevadas transportam o dióxido de carbono dissolvido para as profundezas dos oceanos. Reaparece na região dos trópicos à superfície dos oceanos, passando das águas quentes para a atmosfera. O fitoplancton absorve parte desse $\mathrm{CO}_{2}$ através da fotossíntese, formando o primeiro elo de ligação com a cadeia alimentar marinha. Pequenas quantidades de carbono são depositadas no fundo dos mares, através dos dejectos e dos organismos mortos. Deste processo resulta uma pequena retenção de carbono nos sedimentos oceânicos.

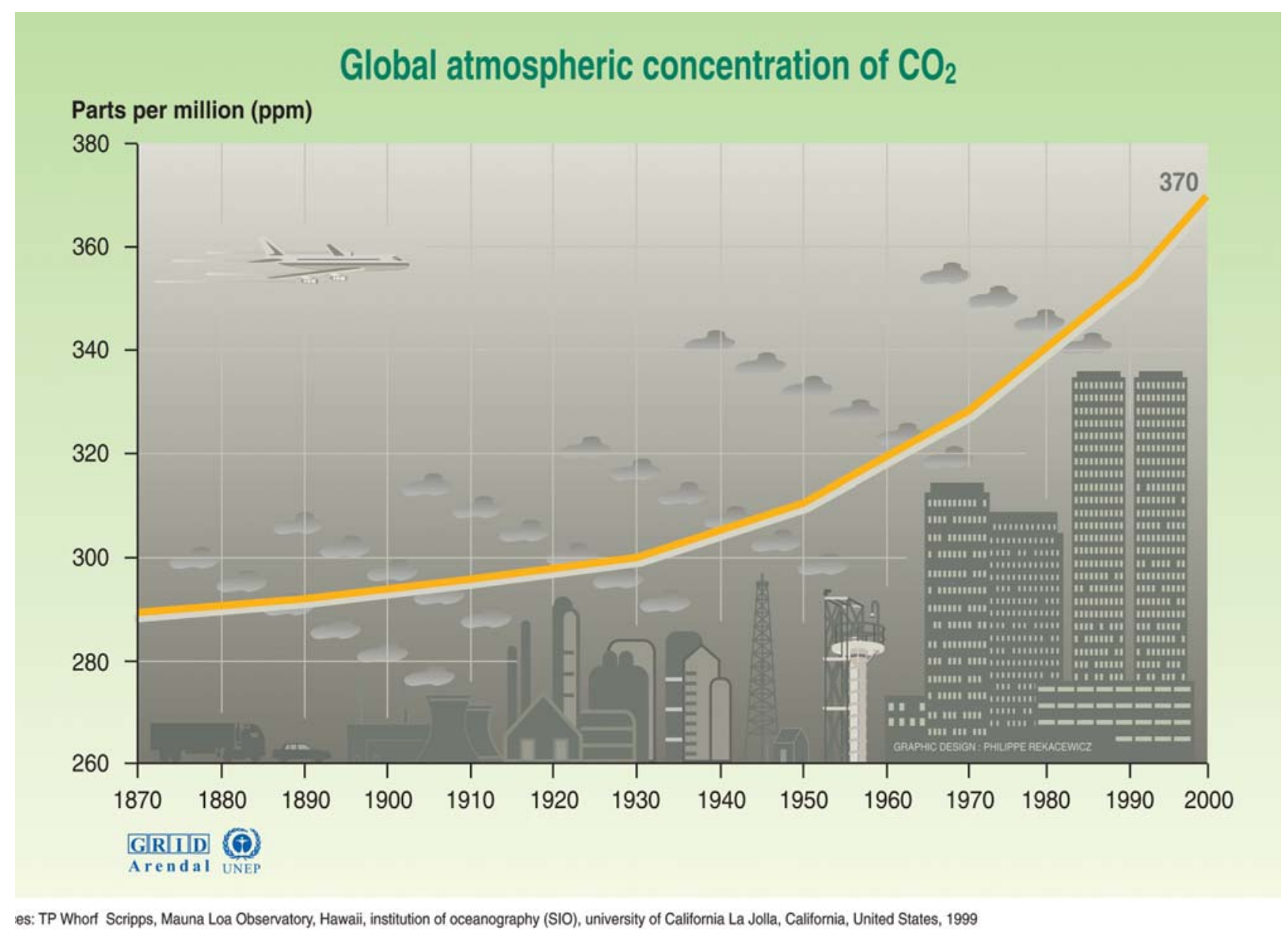

Figura 8 Variação da concentração global de $\mathrm{CO}_{2}$ atmosférico desde 1870 a 2000 em ppmv (fonte: http://maps.grida.no/go/graphic/global-atmospheric-concentration-of-co2) 
Em termos do balanço de carbono (em gigatoneladas por ano):

Depósitos de carbono:

Produção de vegetação: 57

Absorção pelos oceanos: 92,2

Depósitos terrestres: 2,3

Fontes de carbono:

Respiração da vegetação: 55,5

Libertação a partir dos oceanos:

90,5

Emissões por queima de combustíveis fósseis (e produção de cimento): 6,4 ano

Alterações na utilização das terras: 1,2

de que resulta um balanço anual positivo de 2,1 gigatoneladas.

A quantidade de $\mathrm{CO}_{2}$ na atmosfera tem variado significativamente ao longo da história da Terra, em resultado dos efeitos das idades do gelo, vulcanismo, impacto de asteróides e variações da superfície coberta por vegetação.

Há cerca de 500 milhões de anos, a concentração de $\mathrm{CO}_{2}$ na atmosfera pode ter sido cerca de 20 vezes mais elevada do que a actual. Nos últimos 10000 anos a concentração de $\mathrm{CO}_{2}$ tem sido de cerca de 280 partes por milhão, em volume (ppmv) com excepção do aumento que se iniciou com a Revolução Industrial que a elevou para cerca de 380 ppmv.

Refira-se que estudos mais recentes (Tripati et al., Science 326 (2009) 1394)conseguem estimar a concentração de $\mathrm{CO}_{2}$ na atmosfera até há cerca de 20 milhões de anos. Nos últimos 800000 anos, a concentração de $\mathrm{CO}_{2}$ tem oscilado entre $\sim 180$ e $\sim 280$ ppmv, estando estas oscilações correlacionadas com as oscilações da temperatura e do nível dos oceanos. Estes estudos mais recentes mostram que no Mioceno médio (14 a 10 milhões e anos atrás) (em que as temperaturas à superfície da Terra eram cerca de 3 a $6{ }^{\circ} \mathrm{C}$ mais elevadas e o nível do mar 25 a $40 \mathrm{~m}$ mais elevado que actualmente) a concentração de $\mathrm{CO}_{2}$ na atmosfera era idêntica à actual. Durante o Mioceno médio e Plioceno "tardio" ( 3,3 a 2,4 milhões de anos) as reduções da concentração de $\mathrm{CO}_{2}$ coincidiram com a expansão glacial.

Há acordo em relação ao aumento da quantidade de $\mathrm{CO}_{2}$ na atmosfera, mas as opiniões divergem quanto ao seu efeito sobre o aumento médio da temperatura da atmosfera terrestre. Estas previsões baseiam-se em modelos, em relação aos quais surgem vozes discordantes, também porque a escala de tempo habitualmente usada é pequena à escala geológica e

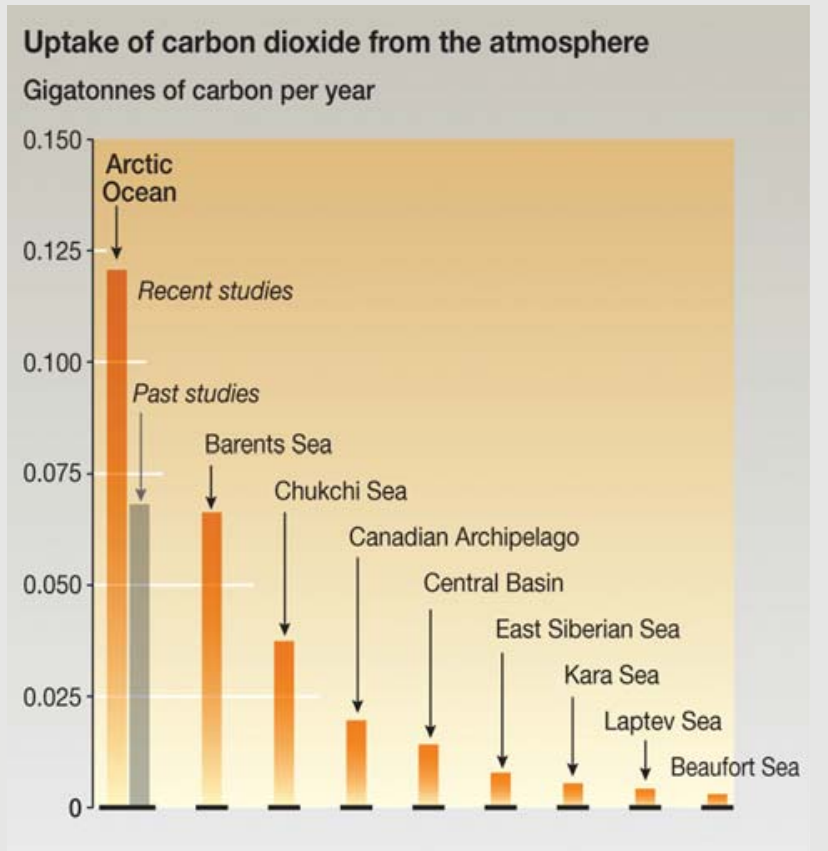

Figura 9 Captura do $\mathrm{CO}_{2}$ atmosférico pelos mares

(fonte: http://maps.grida.no/go/graphic/uptake-of-carbon-dioxide-from-the-atmosphere1) porque não é seguro que tenham em conta todos os intervenientes no ciclo do carbono.

\section{Sequestração de carbono}

Uma das abordagens em desenvolvimento para abrandar o aumento da concentração de $\mathrm{CO}_{2}$ na atmosfera consiste na captação e armazenamento de carbono. Actualmente há alguns projectos em desenvolvimento. A maioria tem por objectivo enterrar 0 $\mathrm{CO}_{2}$ separado do gás natural ou injectá-lo nos reservatórios de petróleo, usando-o para a extracção do petróleo. Há projectos destes em curso ou projectados nos EUA, na Europa, em África (Argélia), na China e Austrália. Em particular, os produtores de gás natural estão a injectar o $\mathrm{CO}_{2}$ comprimido, que separam do gás natural, em depósitos cheios de água e em camadas geológicas a grande profundidade, ou em depósitos de gás natural já esgotados. Há também projectos para reutilização do $\mathrm{CO}_{2}$ proveniente do carvão natural na produção de bebidas gaseificadas.

\section{Carbono proveniente da Queima DOS COMBUSTÍVEIS FÓSSEIS}

O carbono resultante da combustão dos combustíveis fósseis é um dos principais contribuintes para as alterações climáticas. Daí que a captura e armazenamento do carbono envolvido nesta combustão assuma uma grande importância. Contudo, se esta necessidade envolve já um alargado consenso, não é claro que o investimento neste processo seja suficiente. O preço dos combustíveis não tem em conta o preço das emissões do $\mathrm{CO}_{2} \mathrm{e}$, por isso, se os custos de captura e armazenamento fossem reflectidos nesses preços, eles aumentariam e assim os preços de toda a energia consumida. A combustão de combustíveis fósseis satisfaz cerca de $85 \%$ da energia utilizada na actividade industrial.

Para que esta ideia seja implementada são pois necessários investimentos significativos, o que, numa economia de mercado, implica o seu retorno.

Actualmente estão em desenvolvimento três métodos de captura do $\mathrm{CO}_{2}$ provenientes dos combustíveis 
fósseis: pós-combustão, pré-combustão e combustão de oxicombustível. A captura pós-combustão consiste na captura do $\mathrm{CO}_{2}$ com solventes adequados (aminas); na pré-combustão, remove-se o carbono deixando apenas hidrogénio para queimar; a combustão de oxicombustível queima carvão ou gás em ar sem azoto, libertando-se apenas $\mathrm{CO}_{2}$ e água.

Após a combustão, o $\mathrm{CO}_{2}$ é capturado e pressurizado até 70 bar, formando um líquido que pode ser transportado até ao local de armazenamento.

A separação do carbono é o processo que consome mais energia e resulta num maior custo. No caso da pós-combustão, um solvente absorve o $\mathrm{CO}_{2}$, sendo depois regenerado. Estão em estudo aminas como solventes para esta retenção.

Esta técnica baseia-se num processo patenteado em 1930, em que se usam soluções aquosas de uma amina de baixa volatilidade para absorver 0 $\mathrm{CO}_{2}$. A utilização de técnicas criogénicas tem também sido proposta.

A combustão de oxicombustível não foi ainda desenvolvida para grandes instalações. Este método, em que se usa oxigénio criogenicamente separado do ar, permite uma separação mais fácil do $\mathrm{CO}_{2}$, sem solvente. A captura na pré-combustão envolve a gaseificação do carvão ou a transformação química do gás em hidrogénio.

O transporte do $\mathrm{CO}_{2}$ envolve também alguns desafios tecnológicos e comerciais. Tem sido transportado em conduta, mas o material da sua construção tem que ser adequado às características do $\mathrm{CO}_{2}$, nomeadamente, em relação à quantidade de vapor de água e impurezas (como $\mathrm{O}_{2}, \mathrm{~N}_{2}$ ou $\mathrm{SO}_{3}$ ) presentes.

Finalmente, a injecção do carbono e o seu armazenamento geológico, têm que ter em conta a deslocação de fluidos, o arrefecimento que acompanha a sua expansão e que pode resultar na formação de gelo que impede a propagação do $\mathrm{CO}_{2}$ nos depósitos/ reservatórios ou pode provocar a fractura térmica de placas geológicas que confinam o gás.

Embora haja várias instalações experimentais e piloto em funcionamento, não há ainda nenhuma instalação de captura e retenção de carbono a funcionar em pleno.

A sua implementação tem que passar ainda por alguns estágios de desenvolvimento para grandes escalas, sendo que se aspira a que haja instalações comerciais a funcionar em 2015, antes do "prazo limite do clima" de 2020, para evitar que se ultrapasse o ponto de previsibilidade do clima. Para tal são necessários financiamento e a construção de projectos reais urgentes.

\section{Captura do $\mathrm{CO}_{2}$ atmosférico}

As tecnologias acima mencionadas têm por objectivo reduzir a emissão de $\mathrm{CO}_{2}$. Contudo, não podem reduzir (directamente) a sua concentração atmosférica actual nem eliminar os riscos climáticos que daqui derivam. É assim importante conseguirmos reduzir a concentração de dióxido de carbono atmosférico, de uma forma mais rápida do que a natureza consegue.
A atmosfera actual contém cerca de 380 ppmv de $\mathrm{CO}_{2}$ (fracção molar: 0,00314 ou $0,038 \%$ em volume). Sendo esta uma concentração "muito baixa", torna difícil a sua remoção e, por outro lado, é necessário movimentar enormes quantidades de ar. Este é pois um processo mais oneroso do que a captura do $\mathrm{CO}_{2}$ a partir dos gases de combustão, por exemplo. Por isso, de momento, apenas em nichos de actividade muito específicos (produção de energia ou actividade tecnológica) poderá ser economicamente viável a captura do dióxido de carbono atmosférico.

A investigação actual centra-se num pequeno número de grupos académicos e pequenas "start-ups".

A captura pode usar um sistema de absorção sólido (como membranas de permuta iónica ou aminas sólidas) ou líquido (uso de soluções aquosas alcalinas).

Há investidores que acreditam que é possível desenvolver tecnologias competitivas para este fim, que é um dos poucos que permite emissões globais negativas de $\mathrm{CO}_{2}$.

(Adaptado de: Science 325 (2009) 1641. Fontes adicionais: Tripati et al., Science 326 (2009) 1394; Anderson e Bows, Phil. Trans. R. Soc. A 366 (2008) 3863, C\&EN 87 (2009)11; Figuras retiradas de http://maps.grida.no/go/collection/ vital-climate-graphics)

Jorge Morgado 